\title{
Delphi study to identify the young people priorities about digital society
}

\author{
María-José Rodríguez-Conde \\ GE2O, GRIAL Research Group, \\ Research Institute for Educational \\ Sciences, University of Salamanca \\ 37008 Salamanca, Spain \\ mjrconde@usal.es
}

\author{
Alicia García-Holgado \\ GRIAL Research Group, \\ Research Institute for Educational \\ Sciences, University of Salamanca \\ 37008 Salamanca, Spain \\ aliciagh@usal.es
}

\author{
Valentina Zangrando \\ GRIAL Research Group, \\ Research Institute for Educational \\ Sciences, University of Salamanca \\ 37008 Salamanca, Spain \\ vzangra@usal.es
}

\author{
Francisco José García-Peñalvo \\ GRIAL Research Group, \\ Research Institute for Educational Sciences, \\ University of Salamanca \\ 37008 Salamanca, Spain \\ fgarcia@usal.es
}

\begin{abstract}
This paper aims to present an advance of the results of the application of the Delphi technique, with the aim of gathering the opinion of experts or stakeholders on the topics of priority interest of young people in Europe, especially on the digital society. It is a work framed within the Horizon 2020 WYRED Project (netWorked Youth Research for Empowerment in the Digital Society). The WYRED project, and in this specific case the Networking process, aims in bringing together children, young people, other stakeholders and policymakers around Europe. The Delphi technique is one of the prospective methods that study the future, concerning the evolution of the factors of the technosocio-economic environment and the interactions between these factors. The characteristics that define this technique are anonymity, iteration and controlled feedback, and presentation of group data in the statistical form. The progress of the presented results allows us to corroborate the agreement of experts about the topics that have been raised. According to experts, the concern of youth towards issues related to the digital society does not appear among the first concerns of young people neither in Spain nor the rest of the countries surveyed.
\end{abstract}

\section{KEYWORDS}

Digital society, European project, young people, Delphi study,

\section{INTRODUCTION}

Young people do not feel involved in the society and their voices do not reach decision-makers. They are frequently the drivers of new behaviours and understandings and since they are part of the future of society their views and perceptions should be taken into account. WYRED (netWorked Youth Research for Empowerment in the Digital society) [1-3] aims to change this, amplifying youth voices, and connecting them to decision-makers; to help young people research the digital issues that matter to them, so that their concerns are backed up with evidence so that they can have an influence.

WYRED is a European Project funded by the Horizon 2020 programme. It is coordinated by the GRIAL Research Group [4] of the University of Salamanca (Spain) and it started at November 2016 and will be developed along three years, until October 2019 (Table 1).

During the first months of the project, the consortium has set high standards and allocated one of its biggest interests into the creation of a strong and growing Network in order to reach 
more people from diverse backgrounds with different experiences and knowledge. These people/target groups, as the projects foresees, primarily are children and young people who will, by engaging in the process, will get to know better, identify and interact with other stakeholders at policy level and wider society. By involving these diverse groups, WYRED Network tries to connect them and create the space for engagement, collaboration and discussion. In the process of engaging children, young people and stakeholders, the project has set various means to reach out to them and at the same time assure that it includes as many target groups and people as possible.

\section{Table 1. Project details}

\begin{tabular}{|c|c|}
\hline Title & $\begin{array}{l}\text { netWorked Youth Research for Empowerment in the } \\
\text { Digital society }\end{array}$ \\
\hline Acronym & WYRED \\
\hline $\begin{array}{l}\text { Funding } \\
\text { entity }\end{array}$ & European Union \\
\hline Call & $\begin{array}{l}\text { Horizon 2020. Europe in a changing world - inclusive, } \\
\text { innovative and reflective Societies (HORIZON 2020: } \\
\text { REV-INEQUAL-10-2016: Multi-stakeholder platform } \\
\text { for enhancing youth digital opportunities) }\end{array}$ \\
\hline Reference & 727066 \\
\hline Project leader & Francisco José García-Peñalvo \\
\hline Coordinator & University of Salamanca (Spain) \\
\hline Partners & $\begin{array}{l}\text { Oxfam Italia (Italy) } \\
\text { PYE Global (United Kingdom) } \\
\text { Asist Ogretim Kurumlari A.S. - Doga Schools (Turkey) } \\
\text { Early Years - The organisation for young children } \\
\text { LBG (Ireland) } \\
\text { Youth for exchange and understanding international } \\
\text { (Belgium) } \\
\text { MOVES - Zentrum für Gender und Diversität } \\
\text { (Austria) } \\
\text { Boundaries Observatory CIC (United Kingdom) } \\
\text { Tel Aviv University (Israel) }\end{array}$ \\
\hline Budget & $993.662,50 €$ \\
\hline Start date & $01 / 11 / 2016$ \\
\hline End date & $31 / 10 / 2019$ \\
\hline Web & https://wyredproject.eu \\
\hline
\end{tabular}

The networking process included the creation of the WYRED Manifesto, the design of the project logo and slogan, the creation of a promotional video (https://youtu.be/5DE07H vDe8), the initial stakeholders contact and then the implementation of a Delphi study. These phases were the basis of the WYRED project and their outcomes were and are used as the main force and material that supports other processes such as the definition and development of a technological ecosystem to support the research framework [5-7].

Another WYRED objective is to initiate the dialogue process in the project, by identifying the key themes that concern children and young people in relation to desired social change. Different instruments were used to foster engagement and collecting information in order to identify the key themes, but also set the data that assist in preparing for the subsequent activity in the project and also to attract more participants towards WYRED.

In particular, the Delphi study was used to identify and prioritize key areas of interest for young people, and to provide additional insights regarding their involvement in decision making related to their concerns, attitudes and perceptions. The Delphi was carried out in the countries involved in the project (Austria, Belgium, Ireland, Israel, Italy, Spain, Turkey, United Kingdom).

This paper presents the results of the process of elaboration and collection of information on the Delphi study in Spain. The structure of this study, therefore, we have divided into these five parts: an introduction to the general project with the specific objective of this study, an explanation of the methodology used, a presentation of the first progress of results, together with the discussion and conclusions generated in this phase.

\section{METHODOLOGY}

\subsection{Study design}

The information collection technique known as the Delphi technique (expert method) is one of the prospective methods that study the future, regarding the evolution of the factors of the techno-socio-economic environment and the interactions between these factors. In the WYRED project, the scope of the study is the issues that should be considered of greater importance to youth in the digital society.

The Delphi technique consists of the application of successive questionnaires (in this case, only 2) to "expert" people who constitute a panel, to achieve a greater consensus on a topic, without the need to meet in a group.

In the Delphi technique there is specific terminology:

- Circulation. It is each of the successive questionnaires that are presented to the group of experts. In this case, the experts only received two (one semi-structured response) and one closed response.

- Questionnaire. The questionnaire is the document that is sent to the experts. It is not only a document that contains a list of questions, but it is the document with which the experts can interact since it will present the results of previous circulations.

- Panel. It is the group of experts that take part in the Delphi, in this case from 6 countries.

- Moderator. It is the person responsible for collecting the responses of the panel and preparing the questionnaires. In each country, there is a person in charge of translating the answers into English, and there is a supra-moderator who analyzes the responses of all the 
countries together, returning the questionnaires of the next phase.

In any case, the application of a Delphi design assumes at least three characteristics: guarantee the anonymity of the participants and their responses, carry out different iterations, establish the feedback control by the moderator, and the use of statistical techniques in the analysis of the response $[8,9]$.

\subsection{Participants}

In Spain, as in the rest of the countries involved in the study, a group of experts was selected and organized in two groups: stakeholders and young people (from 14 to 29 years old).

This paper presents the results to the two successive surveys of 12 experts (stakeholders) from which a response was received through the two rounds carried out. The expert group was selected, by availability, from the contacts of the research team with secondary education and university teachers, social educators responsible for youth groups, educational administration staff and social welfare in contact with youth, volunteering, etc. Figure 1 shows the distribution of the total sample of experts from the preliminary survey among stakeholders, organized by profession.

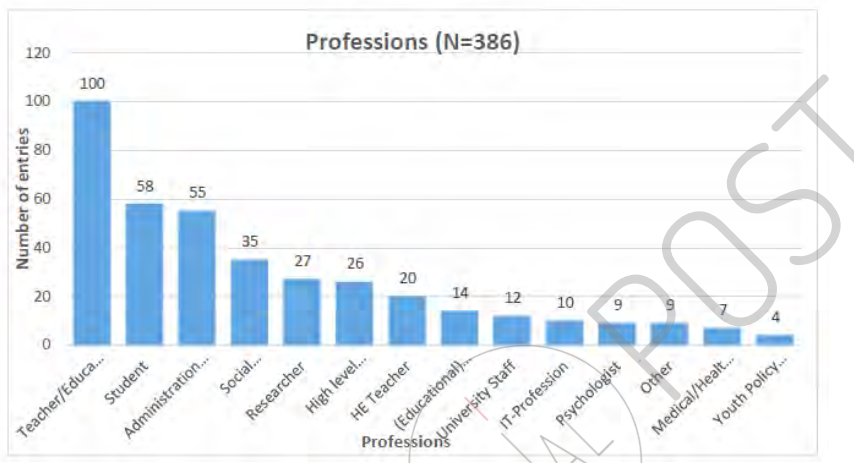

Figure 2: Total sample of experts organized by profession $(\mathrm{N}=386)$. Source: [10]

\subsection{Instrumentation}

$$
\text { [10] }
$$

According to the Delphi method, the survey for stakeholders involved two rounds of online questionnaires. Different questionnaires were developed for the first and for the second round.

The first round consisted of one closed question (rating the most important issues of concern for young people) and additional open questions dealing with ways of engaging young people in decision making and the benefit to society of such engagement [11]. An important input to part of the questionnaire was a preliminary survey among stakeholders [10], carried out in a preceding stage of the project.

The second round consisted of closed questions that were formulated based on responses submitted by the participants in the first round. In this way, the participants in the second round responded to the ideas obtained in the first round, in line with the concept of iterative group interaction, which is the heart of the Delphi method [11].

\subsection{Data collection}

The preliminary survey among stakeholders was implemented through Google Forms and disseminate through the project website, emails, partners and initial contacts. This questionnaire was open from 21st of March till the 8th of April 2017.

Regarding the Delphi study, the questionnaires for both rounds were implemented using a customized version of LimeSurvey (https://www.limesurvey.org), an Open Source online statistical survey web application (Figure 2). The questionnaires were applied in six languages according to the WYRED partner countries (English, German, Hebrew, Italian, Spanish and Turkish).

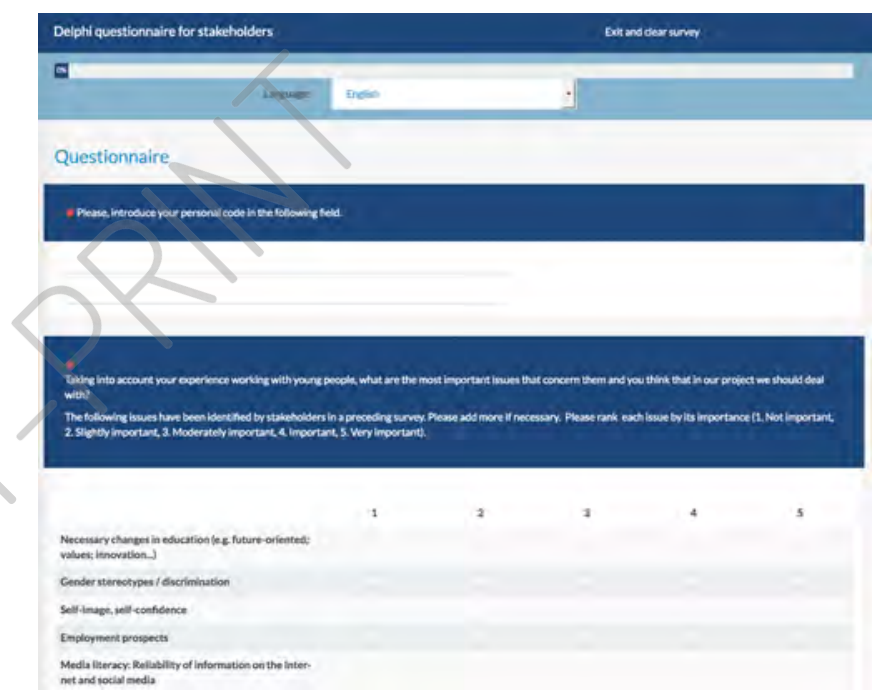

Figure 2. Questionnaire for the first round implemented in LimeSurvey

To analyze the data, two databases in an Excel file were obtained from the automatic entry of results of the questionnaires applied in LimeSurvey. The databases in Excel were imported into the SPSS Statistics 23 (License of the University of Salamanca Campus).

\section{RESULTS}

This section shows some results found in the experts' opinion in Spain, trying to compare their view with the whole of the sample collected in Europe.

In the first place, the first circulation of the questionnaire tried to find out what could be the subjects or contents that most concern current youth, from the opinion of people who are in contact with them in their profession or another type of volunteer activity.

First contents of interest are found in the following order (Table 2): self-image, self-confidence, tolerance to different 
cultures/opinions, and employment prospects. The topics less valued are crime, adults misunderstanding of young people and environmental problems (e.g., pollution). On content related to Technology, an average rating is found, in sixth place Media literacy: Reliability of information on the Internet and social media, follow by cyber-bullying, shaming and internet safety \& privacy.

Table 2: Comparison between the total sample of experts in Delphi, and the sample in Spain, on the most important issues that concern them and WYRED project should deal with (range 1: not important at 5: very important)

\begin{tabular}{|c|c|c|c|c|c|c|}
\hline \multirow{2}{*}{$\begin{array}{l}\text { Delphi technique } \\
\text { Topics }\end{array}$} & \multicolumn{3}{|c|}{ Stakeholders (All) } & \multicolumn{3}{|c|}{ Stakeholders (Spain) } \\
\hline & $\mathrm{N}$ & $M$ & StdDv & $\mathrm{n}$ & $M$ & StdDv \\
\hline [Self-image, self-confidence (4.23)] & 93 & 4.26 & 0.86 & 10 & 4.40 & 0.70 \\
\hline $\begin{array}{l}\text { [Tolerance to different cultures/opinions } \\
(4.12)]\end{array}$ & 93 & 4.11 & 0.88 & 10 & 4.00 & 0.82 \\
\hline [Employment prospects (3.96)] & 93 & 3.97 & 0.97 & 10 & 4.00 & 0.67 \\
\hline [Mental wellbeing (new)] & 93 & 3.92 & 1.01 & 10 & 3.40 & 0.97 \\
\hline $\begin{array}{l}\text { [Necessary changes in education (e.g. } \\
\text { future-oriented) }(3.96)]\end{array}$ & 93 & 3.92 & 0.89 & 10 & 3.70 & 0.95 \\
\hline $\begin{array}{l}\text { [Media literacy: Reliability of information } \\
\text { on the Internet and social media (4.03)] }\end{array}$ & 93 & 3.92 & 1.03 & & 4.00 & 1.05 \\
\hline [Cyber-bullying, shaming (4.20)] & 93 & 3.90 & 1.06 & 10 & 4.30 & 0.95 \\
\hline [Internet safety \& privacy (4.04)] & 93 & 3.85 & & & 4.10 & 0.88 \\
\hline [Gender stereotypes / discrimination (3.91)] & 93 & 3.75 & & 10 & 3.70 & 0.67 \\
\hline $\begin{array}{l}\text { [Causes of stress among young people } \\
(3.74)]\end{array}$ & 93 & 3.70 & & 10 & 3.30 & 0.67 \\
\hline $\begin{array}{l}\text { [Roles of parents, friends and peer groups } \\
(3.62)]\end{array}$ & 93 & 3.68 & 0.89 & 10 & 3.40 & 0.70 \\
\hline $\begin{array}{l}\text { [Integration of migrants/refugees in schools } \\
\text { and in the society }(3.70)]\end{array}$ & 93 & & 1.11 & 10 & 3.40 & 0.97 \\
\hline $\begin{array}{l}\text { [Environmental problems (e.g. pollution) } \\
\text { (new)] }\end{array}$ & 9 & 3.43 & 1.09 & 10 & 3.40 & 1.26 \\
\hline $\begin{array}{l}\text { [Adults misunderstanding of young peop } \\
(3.23)]\end{array}$ & & 3.42 & 1.01 & 10 & 3.10 & 0.74 \\
\hline [Crime (new)] & & 3.19 & 0.99 & 10 & 2.90 & 0.74 \\
\hline
\end{tabular}

Table 3. Comparison between the total sample of experts in Delphi, and the sample in Spain, about the Ways to engage young people in decision-making ( 1 Not at all useful, 2 Slightly useful, 3 Moderately useful, 4 Very useful, 5 Extremely useful)

\begin{tabular}{|l|l|l|l|l|l|l|}
\hline Delphi technique Stakeholders (All) & \multicolumn{2}{l|}{ Stakeholders (Spain) } \\
\hline $\begin{array}{l}\text { Ways to engage young people in decision- } \\
\text { making }\end{array}$ & $\mathrm{N}$ & $\mathrm{M}$ & StdDv & $\mathrm{n}$ & $\mathrm{M}$ \\
\hline $\begin{array}{l}\text { [Direct communication between young } \\
\text { people and decision makers] }\end{array}$ & 93 & 4.30 & 0.84 & 10 & 4.00 & 0.82 \\
\hline $\begin{array}{l}\text { [Fostering active groups in } \\
\text { schools/universities/workplaces } \\
\text { recognition of the activists] }\end{array}$ & 93 & 4.28 & 0.88 & 10 & 4.10 & 1.10 \\
\hline $\begin{array}{l}\text { [Shared projects of self-responsibility (with } \\
\text { family, school, etc.)] }\end{array}$ & 93 & 4.15 & 0.93 & 10 & 4.40 & 0.70 \\
\hline $\begin{array}{l}\text { [Participation in committees, interest groups } \\
\text { etc., together with adults] }\end{array}$ & 93 & 3.97 & 1.04 & 10 & 3.80 & 1.23 \\
\hline $\begin{array}{l}\text { [Using technologies in participatory } \\
\text { processes (including online surveys, voting, } \\
\text { etc.)] }\end{array}$ & 93 & 3.85 & 0.93 & 10 & 3.60 & 0.70 \\
\hline $\begin{array}{l}\text { [Utilization of existing "students' councils", } \\
\text { youth organizations etc.] }\end{array}$ & 93 & 3.74 & 1.02 & 10 & 3.80 \\
\hline $\begin{array}{l}\text { [New representative bodies such as "youth } \\
\text { parliament"] }\end{array}$ & 93 & 3.45 & 1.21 & 10 & 3.40 \\
\hline
\end{tabular}


The valuations among the European experts consulted in the Delphi do not differ much in the first questionnaire applied, when compared with the answers of the Spanish experts (Figure 3). Although it is curious to note that among the responses of Spaniards, the level of importance of the topic on technology obtain values significantly higher than the rest of the countries (media literacy: Reliability of information on the Internet and social media, follow by cyber-bullying, shaming and internet safety \& privacy, is above or equal to 4 on average, over 5 points).

Second, the experts were consulted about: What are the best ways to engage young people in decision-making? The ways proposed during the first round were used as closed options in the second round. The stakeholders rated them by their usefulness (Table 3).

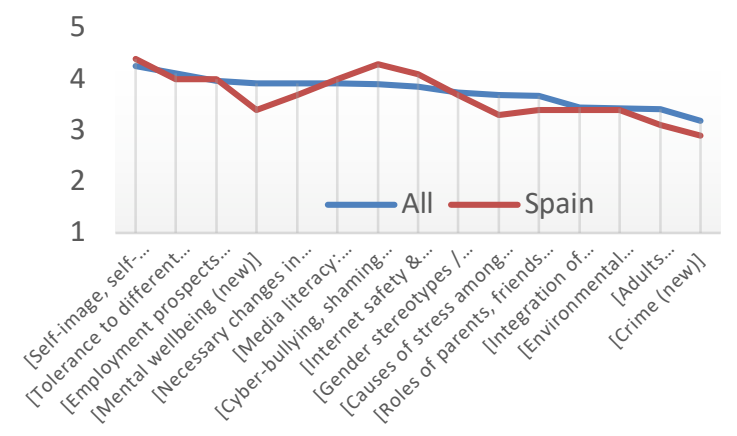

\section{Figure 3: Graphical comparison of average importance to the rated topics, among the total sample of experts in Delphi, and displays it in Spain}

In Table 3 the strategies are ordered, which in the opinion of the European and Spanish experts consulted, could help give voice to young people in Europe. For the group of experts, the most useful measures are: Direct communication between young people and decision-makers, Fostering active groups in schools/ universities/workplaces and recognition of the activists and shared projects of self-responsibility (with family, school, etc.).

For the Spanish experts consulted, it stands out as the most useful measure so that young people's opinions can influence decision-making: shared projects of self-responsibility (with family, school, etc.).

The use of information and communication technologies (ICT), in the opinion of experts, does not seem to be a useful measure in this matter. In the Spanish case, the valuation is even lower.

\section{CONCLUSIONS}

The WYRED Delphi study was focus on identifying the key areas of interest for young people, and to provide additional insights regarding their involvement in decision making processes. The study was implemented in the partner countries. In particular, the Spanish results of the study were analysed.

Regarding the methodology, the application of the Delphi aims to obtain valid and significant results, the researchers should take care and rigor in the following aspects: respect their basic characteristics (anonymity, iteration and controlled feedback, and presentation of the group's data in a statistical way), careful selection of the experts (to apply the biograms and the "coefficient of expert competence"), and to respect the phases of application of the technique.

\section{ACKNOWLEDGMENTS}

With the support of the EU Horizon 2020 Programme in its "Europe in a changing world - inclusive, innovative and reflective Societies (HORIZON 2020: REV-INEQUAL-10-2016: Multi-stakeholder platform for enhancing youth digital opportunities)" Call. Project WYRED (netWorked Youth Research for Empowerment in the Digital society) (Grant agreement No 727066). The content of this publication does not reflect the official opinion of the European Union. Responsibility for the information and views expressed in the publication lies entirely with the authors.

Authors would like to thank their partners at WYRED project for their contributions and support to conduct the study.

\section{REFERENCES}

1] F. J. García-Peñalvo. 2017. WYRED Project. Education in the Knowledge Society 18, 3, 7-14. DOI:http://dx.doi.org/10.14201/eks2017183714.

[2] F. J. García-Peñalvo. 2016. The WYRED Project: A Technological Platform for a Generative Research and Dialogue about Youth Perspectives and Interests in Digital Society. Journal of Information Technology Research 9, 4, vi-x.

[3] F. J. García-Peñalvo and N. A. Kearney. 2016. Networked youth research for empowerment in digital society: the WYRED project. In Proceedings of the Fourth International Conference on Technological Ecosystems for Enhancing Multiculturality (TEEM'16) (Salamanca, Spain, November 2-4, 2016), F.J. GarcíaPeñalvo Ed. ACM, New York, NY, USA, 3-9. DOI:http://dx.doi.org/10.1145/3012430.3012489.

[4] Grial Group. 2018. GRIAL Research Group Scientific Production Report (20112017). Version 2.0. GRIAL Research Group, University of Salamanca.

[5] F. J. García-Peñalvo and Jorge Durán-Escudero. 2017. Interaction design principles in WYRED platform. In Learning and Collaboration Technologies. Technology in Education. 4th International onference, LCT 2017. Held as Part of HCI International 2017, Vancouver, BC, Canada, July 9-14, 2017. Proceedings, Part II, P. Zaphiris and A. Ioannou Eds. Springer International Publishing, Switzerland, 371-381. DOI:http://dx.doi.org/10.1007/978-3-319-58515-4 29.

[6] F. J. García-Peñalvo, Alicia García-Holgado, Andrea Vázquez-Ingelmo, and Antón M. Seoane-Pardo. 2018. Usability test of WYRED Platform. In Learning and Collaboration Technologies. Design, Development and Technological Innovation. 5th International Conference, LCT 2018. Held as Part of HCI International 2018, Las Vegas, NV, USA, fuly 15-20, 2018 Springer International Publishing, Switzerland. DOI:http://dx.doi.org/10.1007/978-3-319-91743-6 5.

[7] J. Durán-Escudero, F. J. García-Peñalvo, and R. Therón-Sánchez. 2017. An architectural proposal to explore the data of a private community through visual analytic. In Proceedings of the 5th International Conference on Technological Ecosystems for Enhancing Multiculturality (TEEM 2017) (Cádiz, Spain, October 18-20, 2017), J.M. Dodero, M.S. Ibarra Sáiz and I. Ruiz Rube Eds. ACM, New York, NY, USA. DOI:http://dx.doi.org/10.1145/3144826.3145398.

[8] J. Cabero Almenara and A. Infante Moro. 2014. Empleo del Método Delphi y su empleo en la investigación en comunicación y educación. Edutec 48, 1-16.

[9] G. Rowe and G. Wright. 1999. The Delphi technique as a forecasting tool: Issues and analysis. International fournal of Forecasting 15, 4, 353-375. DOI:http://dx.doi.org/10.1016/S0169-2070(99)00018-7.

[10] Wyred Consortium. 2017. Initial networking report. WP4_D4.3 Version 0.4.

[11] A. Hauptman and T. Soffer. 2017. WYRED Delphi Study. Results Report. 